\section{Sex and Social Class}

SIR,-Your leading article 21 July, p. 121) rightly makes a plea for sex education which emphasizes personal as well as physical relationships. In some areas excellent programmes have been prepared with this in mind (e.g., "Education for Personal Relationships," Wiltshire County Council Education Committee) but it is my impression that such schemes are exceptional.

In January this year I wrote to every Education Department in the U.K. to suggest that mention should be made of the population crisis during the course of sexeducation in schools. Only about a quarter replied and, while many showed interest in the idea or already included the topic, it was clear that there were many local authority areas in which any form of sex education was still regarded as too controversial.

The difficulty of getting the message across to certain sectors of the community is often increased because outside lecturers tend to be invited to talk to Sixth forms, which are usually well informed and already convinced of the need for contraception. In my small experience they also seem to be canvinced that the world population situation should be one of the factors to be considered by any couple engaged in planning a family.-I am, etc.,

Walsall, Staffs

J. P. Lester

\section{Nasal Polyps}

SIR,-If you will permit a paediatric postscript to your leading article (14 July, p. 63) it is worth noting that nasal polyps, though generally uncommon in children, are quite frequent in cases of cystic fibrosis and are sometimes the presenting feature. The clinical astuteness of one of my E.N.T. colleagues led to the diagnosis of cystic fibrosis not only in a girl with recurring nasal polyposis but also in her apparently healthy brother.-I am, etc.,

R. W. SMITHELLS

University Department of

Paediatrics
Leeds

SIR,-Your leading article (14 July, p. 63) dealt with this subject mainly from a surgical viewpoint, but perhaps mention should have been made of various other aspects of the problem. For instance, the syndrome of nasal polyps, asthma, and aspirin sensitivity; familial nasal polyposis; and the association of nasal polyps with intrinsic asthma would have been interesting subjects worthy of mention.

Allergy seems unlikely to be a major facter in the aetiology of nasal polyps. In a prospective study of 100 consecutive admissions to the Liverpool Ear, Nose and Throat Infirmary, only 10 were considered atopic, an incidence no higher than in the normal population. Rhinorrhoea, sneezing attacks, and recurrent rapidly growing polypi were by no means as rare as your article suggested.

The recommendation for early polypectomy should be accepted with caution. In patients with aspirin sensitivity it has been shown that the onset or aggravation of bronchial asthma follows nasal polypectomy in a suggestive number of patients. ${ }^{1}$ Moreover, in such individuals polypectomy does not control the tendency of the polypi to reform.I am, etc.

David Lewis Northern Hospital,

J. C. Delaney Liverpool Medicine, $1968,68.975$.
and 68 ., Annals of Internal

\section{Penicillin in Leptospirosis}

SIR,-The letter from Dr. R. D. Lockhart (21 July, p. 173) regarding the value of penicillin treatment in leptospirosis reminds me of a clash of opinion on this subject 17 years ago among R.A.M.C. medical specialists working in military hospitals in Malaya.

Fairburn and Semple ${ }^{1}$ reponted a controlled trial of penicillin, chloramphenicol, and conservative non-antibiotic treatment among their patients, using a penicillin dosage of 600,000 units six-hourly, but failed to show a significant difference in the three groups treated. I refused to join the trial as the first patient I treated without antibiotics became so gravely ill with uraemia, severe jaundice, and complete anuria for seven days that I felt it was unethical to continue depriving every thind patient of antibiotics. I treated a series of 20 cases with penicillin 600,000 units four-hourly for five days ${ }^{23}$ and was able to report rapid amelioration of symptoms within 48 hours in all cases. Fourteen patients became apyrexial within 24 hours and all 20 within 48 hours. The average length of stay in hospital was only 14 days. Mackay-Dick and Robinson' also reported a series of 84 cases treated with 600,000 units of penicillin for seven days and they had no deaths or relapses in their group of patients. They had no doubts regarding the efficacy of penicillin.

It might seem that the case for penicillin is still not proven in view of Fairburn and Semple's paper, but on rereading it, though the statistics are not significant and the numbers too small to justify a definite conclusion from them, it does seem that the penicillin-treated cases did better than the others. Their dosage of penicillin was lower than that used by Mackay-Dick and Robinson and myself. I still think that patients with leptospirosis should be given the benefit of the doubt and be treated vigorously with penicillin.-I am, etc.,

LEWIS CIEIN

London W.1

1 Fairburn, A. C., and Semple, S. G., Lancet, 1956, 1, 13.

Clein, L., Lancet, 1956, 1, 289.

Mackay-Dick, J., and Robinson, J. F., Lancet, Mackay-Dick, J.
1957, 2, 346.

Prevalence of Varicose Veins in Africans

SIR,-Dr. A. Rougemont (2 June, p. 547) has presented the results of an investigation undertaken in the Mali Republic in which venous varicosities were found in $10.9 \%$ of 469 African women from a tribal environment, the prevalence rate rising significantly with age. These findings are in contrast to the general belief, referred to by Mr. M. A. Hassan and others (3 March, p. 515), that the incidence of venous disorders in the people of the developing countries of Africa is low.

During a survey of arthritis in a rural Xhosa community in the Transkei, Southern Africa, we examined 297 women aged 18 and over for venous varicosity in the lower limbs. Involvement of the main leg veins was present in $7 \cdot 7 \%$, the prevalence rising with age. The women in this survey came from two adjacent villages and were from the same ethnic stock. However, the pattern of life in one village was extremely unsophisticated, while most of the inhabitants of the other had partially adopted a more Westernized diet and life style. It is of interest that a higher proportion of women with varicose veins was encountered in the latter group (15 out of 145 as against 8 out of 152).

The incidence of $7 \cdot 7 \%$ surprised us because the number of women seeking treatment for varicose veins at the hospital serving the villages in question is extremely low. It is noteworthy that none of the women in the survey complained of any symptoms from their varicose veins, which were well hidden by their long skirts. The fact that there is a low morbidity from varicose veins may account for the belief that the incidence of this condition in the rural African is low, whereas in actual fact it may be appreciable.-We are, etc.,

St. Lucy's Hospital,

GuY DAYNES Transkei

Debartment of Human Genetics, Peter BeightoN

Medical School,

University of Cape Town

\section{Classification of Skin Diseases}

SIR,-I consider that the time has come for a simpler classification of skin conditions and suggest that this could be: (A) Conditions in which betamethasone and allied preparations are contraindicated. (B) Conditions in which betamethasone and allied prepanations are not helpful but do no harm. (C) Other conditions.

Such a classification would be most useful to the practising physician and simplify a subject which, in many ways, is unnecessarily complicated.-I am, etc.

Edinburgh

E. RONALD SEILER

Prescription Charges in Chronic Illness

SIR,-Further to the letter from Dr. L. A. Liversedge (21 July, p. 175) about prescription charges for patients with Parkinsonism I should like to point out that the situation described by Dr. Liversedge applies also to coeliacs. This society has met the same blank wall of refusal from the Department of Health and Social Security, who blame the relevant committee of the B.M.A. for, not agreeing to a wider category of illnesses qualifying for exemption than exists at the moment.

It is surely time that patients with chronic complaints such as Parkinson's disease and coeliac disease requiring a specific treatment were put on the same 